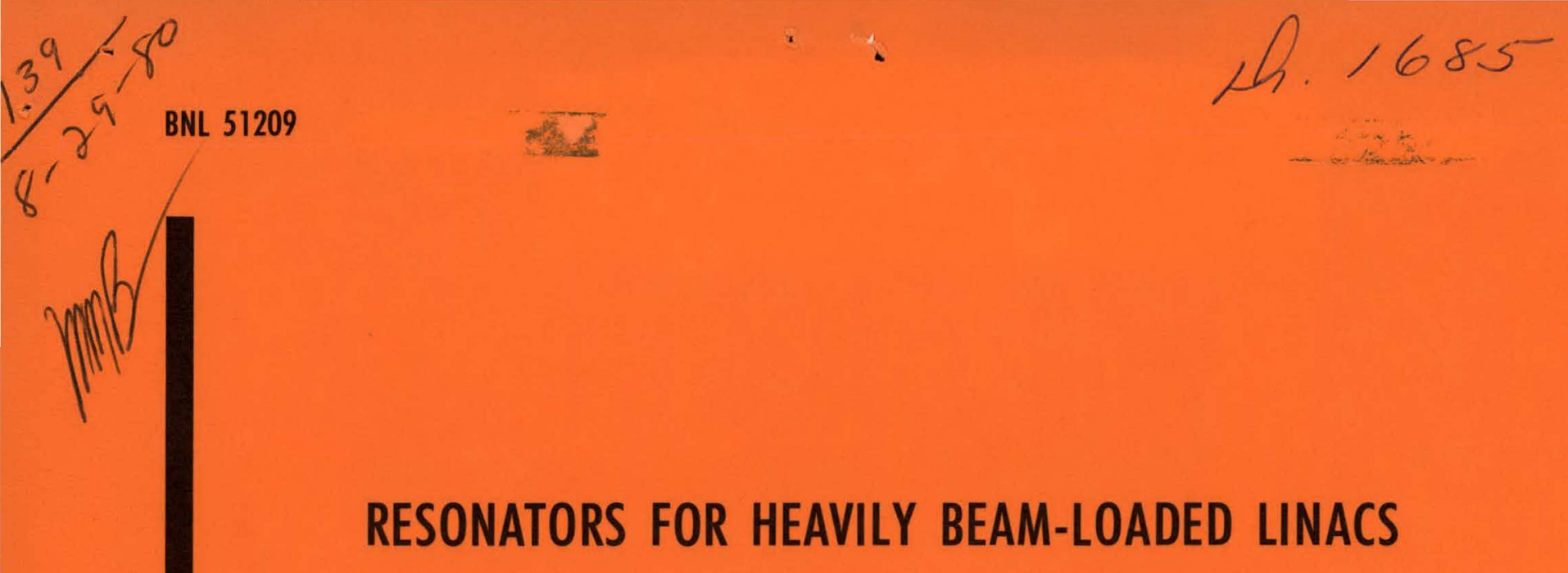

\author{
RALPH T. SANDERS
}

April 28, 1980 


\section{DISCLAIMER}

This report was prepared as an account of work sponsored by an agency of the United States Government. Neither the United States Government nor any agency Thereof, nor any of their employees, makes any warranty, express or implied, or assumes any legal liability or responsibility for the accuracy, completeness, or usefulness of any information, apparatus, product, or process disclosed, or represents that its use would not infringe privately owned rights. Reference herein to any specific commercial product, process, or service by trade name, trademark, manufacturer, or otherwise does not necessarily constitute or imply its endorsement, recommendation, or favoring by the United States Government or any agency thereof. The views and opinions of authors expressed herein do not necessarily state or reflect those of the United States Government or any agency thereof. 


\section{DISCLAIMER}

Portions of this document may be illegible in electronic image products. Images are produced from the best available original document. 
BNL 51209

UC-28

(Particle Accelerators and

High-Voltage Machines - TID 4500)

\title{
RESONATORS FOR HEAVILY BEAM-LOADED LINACS
}

\author{
RaLPH T. SANDERS
}

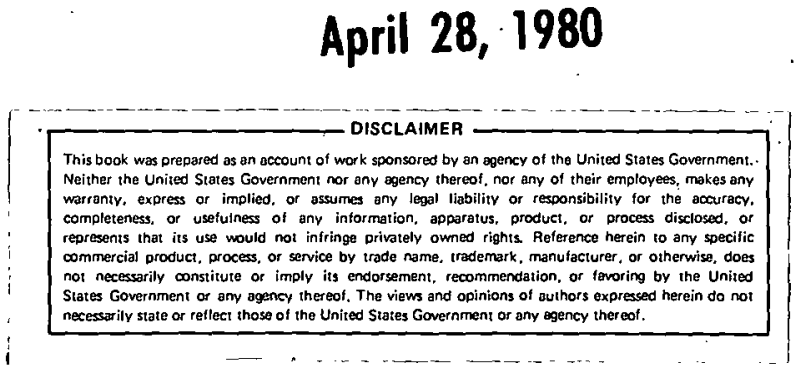

\section{ACCELERATOR DEPARTMENT}

BROOKHAVEN NATIONAL LABORATORY

ASSOCIATED UNIVERSITIES, INC.

UPTON, NEW YORK 11973

UNDER CONTRACT NO. DE-AC02-76CHO0016 WITH THE

UNITED STATES DEPARTMENT OF ENERGY 
THIS PAGE

\section{WAS INTENTIONALLY LEFT BLANK}




\section{ABSTRACT}

Capacitively loaded resonant line section accelerating structures are discussed. Prototype models were measured at low'levels, and calulations were made to predict high level operation. High current composite beams of multiple-beamlets as accelerated by a MEQALAC were assumed. 


\section{INTRODUCTION}

This study is a preliminary step in work that might lead to future investigations and prototyping. It is introductory in that it includes calculations, low level laboratory measurements, and recommendations but does not test and finalize a full power model.

The feasibility of designing resonators of known technology as coupling elements, is not necessarily noteworthy with respect to the state of the radiofrequency engineering art; but it is important to study those aspects of these devices that might present pitfalls in their successful utilization as part of the accelerating structure of heavily beam loaded machines. Also, perceptive and intuitive studies of these early models will lead to more innovative and, in turn, more economical final designs.

\section{II . GENERAL}

Important aspects of resonator design that must be investigated when heavy beam loading is a prime consideration include the excitation of harmonically related modes, matching from no-load to full-load conditions, frequency shift with changing beam current, transmission of $r f$ power, stored energy, heat transfer, and mechanical stability. Not all of these could be studied because high level tests were not performed; however, low level tests did give some insight into the kinds of problems to be anticipated.

The design study dwells on parameters for models that are not just hypothetical but are chosen because the required beam current is realizable with present-day technology. The frequency range and predicted power levels are within the capabilities of an existing high frequency radio transmitter that could be used as a power source in a continuation of this study.

Design Specifications:

Proton or $\mathrm{H}^{-}$beam current

[nergy level of initial beam

Peak rf gap voltage

Number of accelerating gaps

Gap length

Energy gain
2 amperes

$20 \mathrm{keV}$

$6.5 \mathrm{kV}$

2

$1 \mathrm{~mm}$

$9 \mathrm{keV}$ 
Frequency

Cell length

Duty factor
$50 \mathrm{MHz}$

$\beta \lambda / 2$

Continuous

Until recently, the state of low beta accelerator technology would have precluded the study of high current machines. However, the development of the MEQALAC concept has opened new avenues of study that until now would not have been deemed prudent. A discussion of MEQALAC principles is beyond the scope of this paper. For the unfamiliar, it suffices to say that it is a working scheme that incorporates multiple low current beamlets in parallel elctrostatically focuscd channels, to obtain high current beams. 1

\section{STRUCTURE CONFIGURATION}

The modular accelerating structure and resonator assembly compise an unusual approach to accelerator design. Figure 1 shows a typical assembly.

A multiplicity of these structures can easily be paralleled to increase the total beam current. Also, because of the transition from resonator section to gap section, they may be assembled in an inverse series configuration, as shown in Figure 2. Electrostatically focused beam transports are inserted between gap sections and inside each drift tube.

For more orthodox systems, where these structures are used in series, the vacuum handling could be done with a conventional single channel vacuum pipe. Where a number of units are paralleled, it would be quite simple to house the whole accelerator in a single large vacuum chamber.

The form of the drift tube and accelerating gaps is dictated by the multiple beams and their quadrupole channels. Fxperience gained from ongoing electrostatic quadrupole development has shown the mnst. simplifient configuration for many beams to be a square or a rectangle. Figure 3 shows a typical multiple beam drift tube and its accelerating gaps.

For our studies the "face" of the drift tube was fixed at 4 inches square. The capacitance of the two $1-\mathrm{mm}$ gaps is large (180 pF). This causes a significant foreshortening of the resonator.

Figure 4 shows the complete assembly. The overall dimensions were roughly approximated to quickly obtain a model for laboratory measurements that would be near $50 \mathrm{MHz}$. 


\section{PROTOTYPE MEASUREMENTS AND CALCULATIONS}

The capacitance of the line section was measured as $1.38 \mathrm{pF} / \mathrm{cm}$. The characteristic impedance then is:

where:

$$
\begin{aligned}
& z_{0}=\frac{1}{C_{0} v}=\frac{1}{1.38 \times 10^{-12} \times 3 \times 10^{10}} \\
& z_{0}=24.2 \text { ohms }
\end{aligned}
$$$$
\begin{aligned}
& C_{0}=1.38 \mathrm{pF} / \mathrm{cm} \\
& v=3 \times 10^{10} \mathrm{~cm} / \mathrm{sec}
\end{aligned}
$$

The per unit inductance of the line is:

$$
\begin{aligned}
& L_{0}=C_{0} Z_{0}^{2} \\
& L_{0}=\left(1.38 \times 10^{-12}\right)(24.2)^{2} \\
& L_{0}=8.064 \times 10^{-10} \mathrm{H} / \mathrm{cm}
\end{aligned}
$$

The lumped circuit equivalents for the line resonator can now be determined, and are shown in Figure 5.

Where the line length is $18^{\prime \prime}$, the total inductance is:

$$
L^{\prime}=L_{0} \times \ell=8.064 \times 10^{-10} \times 18 \times 2.54=3.69 \times 10^{-8} \mathrm{H}
$$

The effective capacitance of the distributed capacitance plus the gap capacitance is: 2

$$
\begin{aligned}
& C^{\prime}=\frac{1}{2}\left[C_{\text {ext }}+\frac{C_{0} \ell}{\sin ^{2} \theta}\right] \\
& C^{\prime}=\frac{1}{2}\left[180 \mathrm{pf}+1.38 \frac{\mathrm{pF}}{\mathrm{cm}} \times 45.72 \mathrm{~cm} \cdot \frac{1}{\sin ^{2} 32^{\circ}}\right] \\
& C^{\prime}=\frac{1}{2}\left[180+\frac{63.09}{\sin ^{2} 32^{\circ}}\right]=\frac{1}{2}[180+224.7] \\
& C^{\prime}=202 \mathrm{pF}
\end{aligned}
$$

The resonant frequency of the structure was measured as:

$$
f_{0}=58.213 \mathrm{MHz} \text {. }
$$


and the no-load Q:

$$
Q_{n L}=1174
$$

Normally a quarter wave section, those with small capacitive loading in particular, would have an infinite number of higher order modes of odd quarter wavelengths such as $\lambda / 4,3 \lambda / 4,5 \lambda / 4,7 \lambda / 4$, etc. A high current beam pulse could easily excite some of these modes. By using heavy capacitive gap loading, a form of mode-suppression is accomplished. 3

Using the relationship for the input impedance of a shorted line section:

$$
z_{i n}=j z_{0} \tan \left(\frac{2 \pi l}{\lambda}\right)
$$

where

$$
\begin{aligned}
& z_{\text {in }}=X_{c} \text { gap: } \\
& \frac{1}{w c}=z_{0} \tan \left(\frac{2 \pi \ell}{\lambda}\right)=z_{0} \tan \theta
\end{aligned}
$$

The electrical length of the line is:

$$
\begin{aligned}
& \theta=\tan ^{-1} \frac{1}{Z_{0}^{2 \pi f c}} \\
& \theta=\tan ^{-1}\left(\frac{1}{24.2 \times 2 \times \pi \times 58.69 \times 10^{6} \times 180 \times 10^{-12}}\right) \\
& \theta=\operatorname{tanl}^{-1} 0.623=32^{\circ}
\end{aligned}
$$

where $f_{\text {meas }}=58.69 \mathrm{MHz}$

The electrical length is short, and we know intuitively that whatever modes are present, they will not be harmonics of $f_{0}$. Further verification is obtained by treating the gap area of the resonator as a low impedance line 
section connected to a higher impedance shorted line section. We can then solve for the input impedance of a compound line. Refer to Figure 6 .

The input impedance is given by:

$$
z_{i n}=j z_{1} \tan \left[\theta_{1}+\tan ^{-1}\left(\frac{z_{2}}{z_{1}} \tan \theta_{2}\right)\right]
$$

where:

$$
\begin{aligned}
& \theta_{1}=\frac{l_{1}}{\lambda}\left(360^{\circ}\right) \\
& \theta_{2}=\frac{l_{2}}{\lambda}\left(360^{\circ}\right) \\
& z_{1}=1.88 \text { ohms (estimated from curves) } \\
& z_{2}=24.2 \text { ohms }
\end{aligned}
$$

Solving for $Z_{\text {in }}$ for frequencies from 25 to 350 megahertz, the curve of Figure 7 was obtained. Both poles are close to measured values. $337 \mathrm{MHz}$ falls nicely between $5 \lambda / 4$ and $7 \lambda / 4$.

\section{POWER AND ENERGY CONSIDERATIONS}

Using the specifications of Section II, high level operation of the resonator can now be ascertained with reasonable accuracy.

The shunt resistance of the resonator is:

$$
\begin{aligned}
& Q_{n L}=\frac{R_{S h}}{X}={ }_{\omega} C^{\prime} R_{S h} \\
& R_{s h}=\frac{Q_{n L}}{\omega C^{\top}}=\frac{1174}{2 \pi \times 50 \times 10^{6} \times 202 \times 10^{-12}}=18.6 \times 10^{3} \text { ohms }
\end{aligned}
$$

Resonator power dissipation:

$$
P_{\text {res }}=\frac{V_{r f}{ }^{2}}{2 R_{s h}}=\frac{(6500)^{2}}{\left(18.6 \times 10^{3}\right)}=1136 \text { watts }
$$


Beam loading:

$$
P_{\text {beam }}=V_{\text {gap }} \times I_{\text {beam }} \times 2 \text { gaps }=4500 \times 2 \times 2=18 \mathrm{~kW}
$$

The effective shunt resistance at full-load is:

$$
\begin{aligned}
& R_{\text {sh }}=\frac{V^{2}}{2 P}=\frac{(6500)^{2}}{2\left(18 \times 10^{3}\right)}=1174 \text { ohms } \\
& Q_{f L}=\frac{Q_{n L} \times R_{s h ~ f L}}{R_{\text {sh } n L}}=\frac{(1174)(1174)}{18600}=74
\end{aligned}
$$

Where the generator is closely coupled and properly matched:

$$
Q_{f L} \sim 37
$$

and,

$$
R_{\text {sh }} \approx 587
$$

Energy imparted to beam:

$$
\begin{aligned}
& \int_{t 1}^{t 2} P_{\text {beam }} d t=P_{\text {beàlI }} \times \frac{1}{r} \\
& w_{\text {beam }}=\frac{18 \times 10^{3}}{50 \times 10^{6}}=.36 \times 10^{-3} \text { joules }
\end{aligned}
$$

Energy stored in accelerating gaps:

$$
\begin{aligned}
& W_{\text {gap }}=\frac{1}{2} C v^{2} \\
& W_{\text {gap }}=\frac{1}{2}\left(180 \times 10^{-12}\right)\left(4.5 \times 10^{3}\right)^{2}=1.823 \times 10^{-3} \text { juule }
\end{aligned}
$$

The energy given to the beam is about $20 \%$ that which is stored in a pair of gaps. 
The rf current at the gap is:

$$
\begin{aligned}
& I=\frac{V_{p k}}{X_{c \text { gap }}}=2 \pi f c \cdot V_{p k} \\
& I=2 \pi \times 50 \times 10^{6} \times 180 \times 10^{-12} \times 6.5 \times 10^{3} \\
& I=368 \mathrm{~A}
\end{aligned}
$$

The rf current at the shorted end of the line is:

$$
I_{s C}=\frac{368}{\sin 32^{\circ}}=434 \mathrm{~A}
$$

Figure 8 shows the rf current distribution in the line.

A circuit model of the $r f$ generator, resonator and beam is given in Figure 9. Using this model and with the vector diagrams of the figures that follow, the effects of heavy beam loading can be determined. 4

Without beam, and with the resonator tuned, the gap voltage and associated currents are shown in Figure 10. The resonator current $I_{c}$ is small and only supplies the structure losses. Where:

$$
I_{G}=I_{C}=\frac{V_{C}}{R_{S h}}=\frac{6500}{18.6 \times 10^{3}}=0.35 \mathrm{~A} \text { peak }
$$

The maximum beam current occurs at the stable phase angle $\phi$. If it is assumed that this current is the fundamental fourier component, and is about twice the average beam current, then:

$$
I_{b} \sim 4 \mathrm{~A} \text { peak }
$$

Figure 11 shows the beam current and resulting generator current $I_{G}$ with the resonator tuned. With a stable phase angle of $45^{\circ}$, solving the vector diagram, we get:

$$
I_{G}=4.26 \mathrm{~A} \quad 41.6^{\circ}
$$


If the resonator is detuned so that $I_{C}$ has both a real and an imaginary term:

$$
I_{C}=V_{C} \cdot+J V_{C} B
$$

Then, as shown in figure 12, $I_{G}$ is now in phase with $V_{C}$. Then:

$$
I_{G}=V_{c} G+I_{b} \sin \phi=(0.35+2.828) A=3.18 \mathrm{~A} \text { peak }
$$

Power from the generator is then:

$$
P=\frac{V_{C} I_{G}}{2} \times 2 \text { gajs }=\frac{6500 \times 3.18}{2} \times 2=20.7 \mathrm{~kW}
$$

The current through susceptance $B$ is:

$$
V_{c} B=-j I_{b} \cos \phi=-j 2.828 A \text { peak }
$$

Susceptance B is:

$$
B=\frac{V_{c} B}{V_{c}}=\frac{-j 2.828}{6500}=\frac{1}{j 2300}
$$

We can now determine the resonant frequency and the frequency shirt of the resonator caused by detuning.

$$
f_{0}=\frac{1}{2 \pi \sqrt{L^{\prime} C^{\prime}}} \sqrt{\frac{L^{\prime}-C^{\prime}\left(R_{\text {ser }}\right)^{2}}{L^{\prime}}}
$$

But:

$$
R_{\text {ser }}=\left(\frac{R_{s h}}{1+Q^{2}}\right)
$$

The for no beam: (with the coupling matched for full load). where:

$$
\begin{aligned}
& Q_{N L}=74 \\
& R_{S H}=1174 \text { ohms }
\end{aligned}
$$




$$
\begin{aligned}
& L^{\prime}=3.69 \times 10^{-8} \mathrm{H} \\
& C^{\prime}=202 \mathrm{pF} \\
& f_{1}=58,288,740 . \mathrm{Hz} \text { (without beam) }
\end{aligned}
$$

But the resonant frequency will shift slightly when the beam is present:

$$
f_{2}=58,268,657 \text { (with beam) where: }
$$

$$
\begin{aligned}
& Q_{f L}=37 \\
& R_{\text {sh }}=587 \text {. ohms }
\end{aligned}
$$

However, to correct the power factor, the resonator has been detuned to a new frequency $f_{3}$ when beam is present. Having found the susceptance of the new reactive term, we can solve for the change in tuning capacitance. Where:

$$
Y_{\text {in }}=\frac{1}{Z_{\text {in }}}=\frac{1}{R}+\frac{1}{X_{C}}+\frac{1}{X_{L}}
$$

Also:

$$
Y_{\text {in }}=G+J B
$$

Using the above equations and equating the imaginary terms:

$$
\begin{aligned}
& \frac{1}{X_{C}}+\frac{1}{X_{L}}=j B \\
& \text { where: } \\
& B=\frac{1}{j 2300} \\
& \frac{1}{j 2300}=\frac{1}{j 2 \pi f L}-\frac{2 \pi f c}{j} \\
& f=58.3 \mathrm{MHz} \\
& C=\frac{1}{(2 \pi f)^{2} L}-\frac{1}{2 \pi f(2300)} \\
& C=\frac{1}{\left(1.342 \times 10^{17}\right)\left(3.69 \times 10^{-8}\right)}-\frac{1}{\left(3.663 \times 10^{8}\right)(2300)} \\
& C=201.93 \times 10^{-12}-1.187 \times 10^{-12}=200.75 \mathrm{pF}
\end{aligned}
$$

The change in capacitance caused by detuning is:

$$
(202-200.75) \cdot \mathrm{pf}=1.25 \mathrm{pF}
$$

Frequency $f_{3}$ is then: 


$$
\begin{aligned}
& f_{3}=58,423,378 \mathrm{~Hz} \quad \text { where: } \\
& Q_{\mathrm{fL}}=37 \\
& R_{S h}=587 \\
& C^{\prime}=200.75 \mathrm{pF} \\
& L^{\prime}=3.64 \times 10^{\prime}-8 \mathrm{H}
\end{aligned}
$$

The resonant frequency change is then:

$$
f_{3}-f_{1}=135 \mathrm{kHz}
$$

The 3-dB bandwidth is:

$$
\frac{f_{0}}{Q_{f L}}=\frac{58.4 \times 10^{6}}{37}=1.58 \mathrm{MHz}
$$

The relative response of the resonator is shown in figure 13 .

\section{OTHER CONSIDERATIONS}

\section{A. Thermal Effect}

The resonator dissipation at high levels would be on the order of $1 \mathrm{~kW}$. Water cooling could easily keep both the inner and outer conductors at close to equal temperatures. The coefficient of frequency variation will correspond to the mechanical temperature coefficient of linear expansion. Assuming that both conductors are made of the same material, the line constants per unit length will not change. However, their length will change. Also, there will be local heating at the accelerating gaps by particle bombardment. These combined effects will causise the resonant frequericy to change, but since the temperature coefficient of copper is about 16 parts per million per degree $C$, such changes will be orders of magnitude smaller than the detuned frequency shift. 5

The field free channel of the center conductonr can easily accommodate water cooling tubes for the drift-tube assembly and the line itself.

B. Air Versus Vacuum

Up to this point it has been assumed that the complete line is under vacuum. While this sounds like a simple approach, it is not without its problems. If the rectangular line section is pumped down, then it is structurally more difficult to build. Also, since the beam current, as in . most accelerators, increases with improvements over a perfod of time, the of coupling must also be changed through some kind of vacuum window. Vacuum is not a necessity in the line section for voltage hold off. 
An alternative approach to the resonator design would be to make a transition from the rectangular gap section to a cylindrical coaxial line section. A vacuum window at the transition point is easily accomplished. This configuration allows the rf coupling loop to be in air and is simpler to make adjustable.

\section{Input Coupling}

Going one step further, if the center conductor of the line section is placed off-center so that an eccentric line is formed, the clearances between the coupling loop and line section elements can be made larger and require less manufacturing precision. Figure 14 shows a typical eccentric line resonator. Particular note should be given to the coupling loop which can be rotated and also since the $\mathrm{rf}$ input power could be as high as $20 \mathrm{~kW}$, the input line (1-5/8" rigid coax) becomes almost a formidable size.

Because the line is short, the magnetic field is almost uniform. The area of the coupling loop for the proper impedance levels can be determined from a simple transformer relationship.

$$
z_{\text {in }}=\left|\frac{a}{b}\right|^{2} R_{s h}
$$

where

$$
\begin{aligned}
& a=\text { distance from tap to shorted end } \\
& b=\text { distance from open end to closed end. }
\end{aligned}
$$

A long loop coupling, while it is easy to build and adjust, does have some disadvantages. As it is turned, it causes tuning changes because of some capacitive coupling to the line. Also, when it is formed from a rod, it tends to mechanically oscillate from side to side with vibrations, causing modulation of the rf. A loop of flat strip would lessen this problem. Finally, the usable variations of the physical configuration are limited because the rf currents are high (in this case $20 \mathrm{~A}$ ) and it is desirable to avoid moving contacts.

Figure 15 shows an eccentric line model built for laboratory tests. The line section was placed at 90 degrees to the drift tube but could easily have been put on the same axis. Low level measurements of this model did not differ much from those of the rectangular line. Non-uniform current density caused by the eccentric section did not lower the $Q$ (measured at 1000), from a coaxial model of identical conductor dimerisions. 
The right-angle joint between the line and gap sections did not cause any spurious modes to be excited.

The inductance of the long coupling loop measured 0.3 microhenries. There was concern that some series capacitive element (stub or capacitor) would be required to "tune out" this appreciable inductance in order to obtain a low VSWR. 6 This was not the case. Actually a VSWR of 1.2 to 1 . was possible by rotating the loop.

\section{CONCLUSION}

Low level measurements and calculations verify the useability of heavily beam loaded resonators. Successful application requires sufficient gap capacitance to suppress unwanted harmonically related modes, even heavier capacitive loading may be a requisite so that the gaps will store enough energy so that beam loading is not a noticeable effect.

The inherent losses of the structure are small, but when combined with whatever heating might be incurred from the beam, even a small resonant frequency change could be significant. The continuation of this study at high levels with a test beam should be made to verify the calculated beam loading effects.

Thought should also be given to the operational modes, i.e., what coupling and matching schemes could be used to accumludate turn-on, turn-off, loading changes, beam loss, etc.

\section{ACKNOWLEDGMENTS}

Many thanks to J.T. Keane for his helpful suggestions, and to K. Riker and J. Boruch for their skillful construction.

\section{REFERENCES}

1. Maschke, A.W., MEQALAC: A New Approach to Low Beta Arc.eleration, BNL 51029, June $197 \overline{9}$.

2. Strutt, M.J., UItra- and Extreme-Short Wave Reception, p. 155, pp. 379-81. Van Nostrand, New York, 1947.

3. Staff, Radio Research Laboratory, Harvard University, Very High-Frequency Techniques, pp. 922-5, McGraw-Hi11, New York, 1947. 
4. Nassibian, G., CERN SI/Note EL/69-5, June 1969.

5. Hanse11, C.W. and Carter, P.S., Frequency control by low power factor line circuits, Proc. I.R.E. 24, 597-619 (1936).

6. Staff, Radio Research Laboratory, pp. 379-381. 


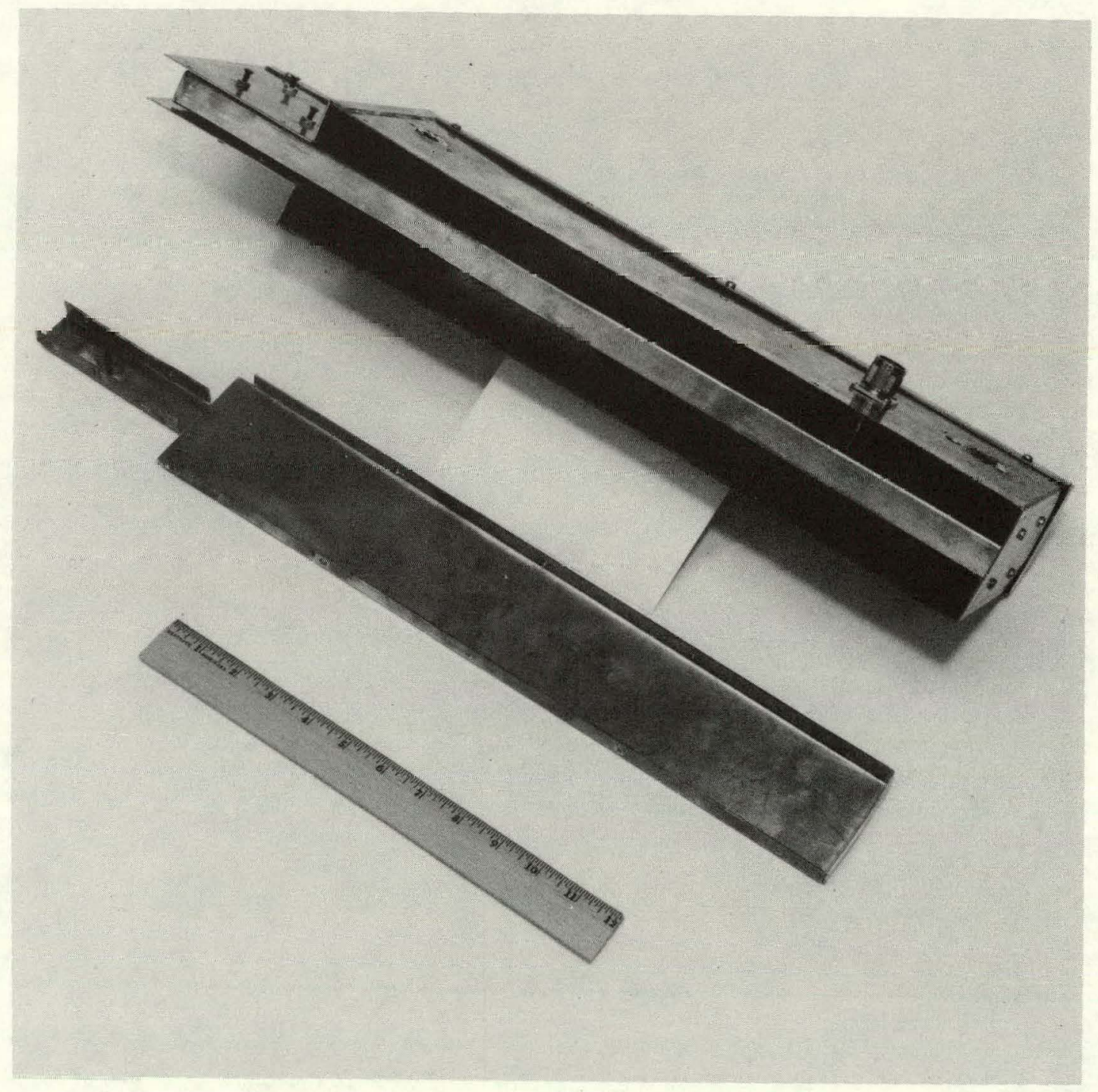

Figure 1. Modular Accelerating/Kesonator Strucluse 


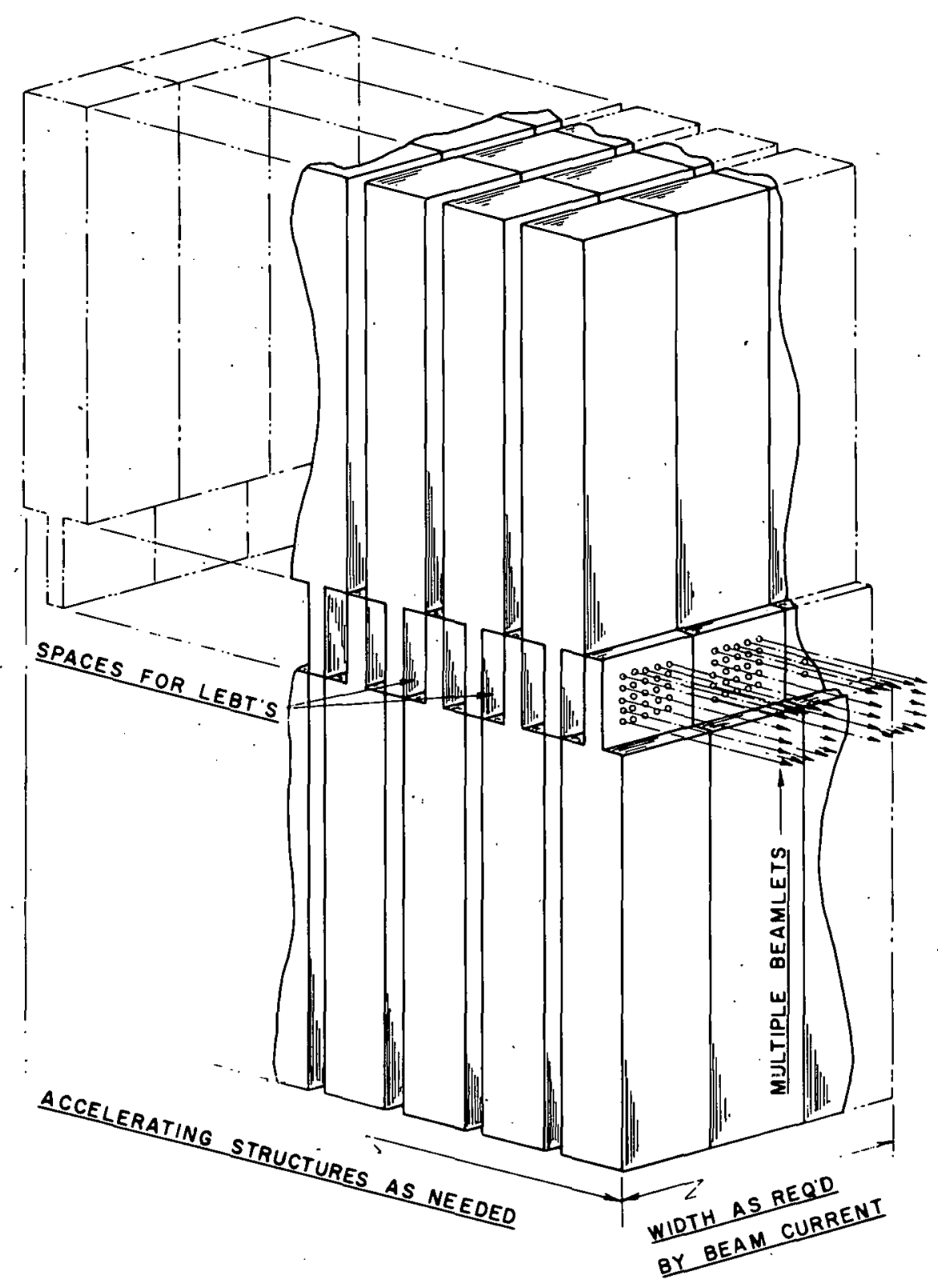

Figure 2. Modular Accelerating Structure Array Configuration 


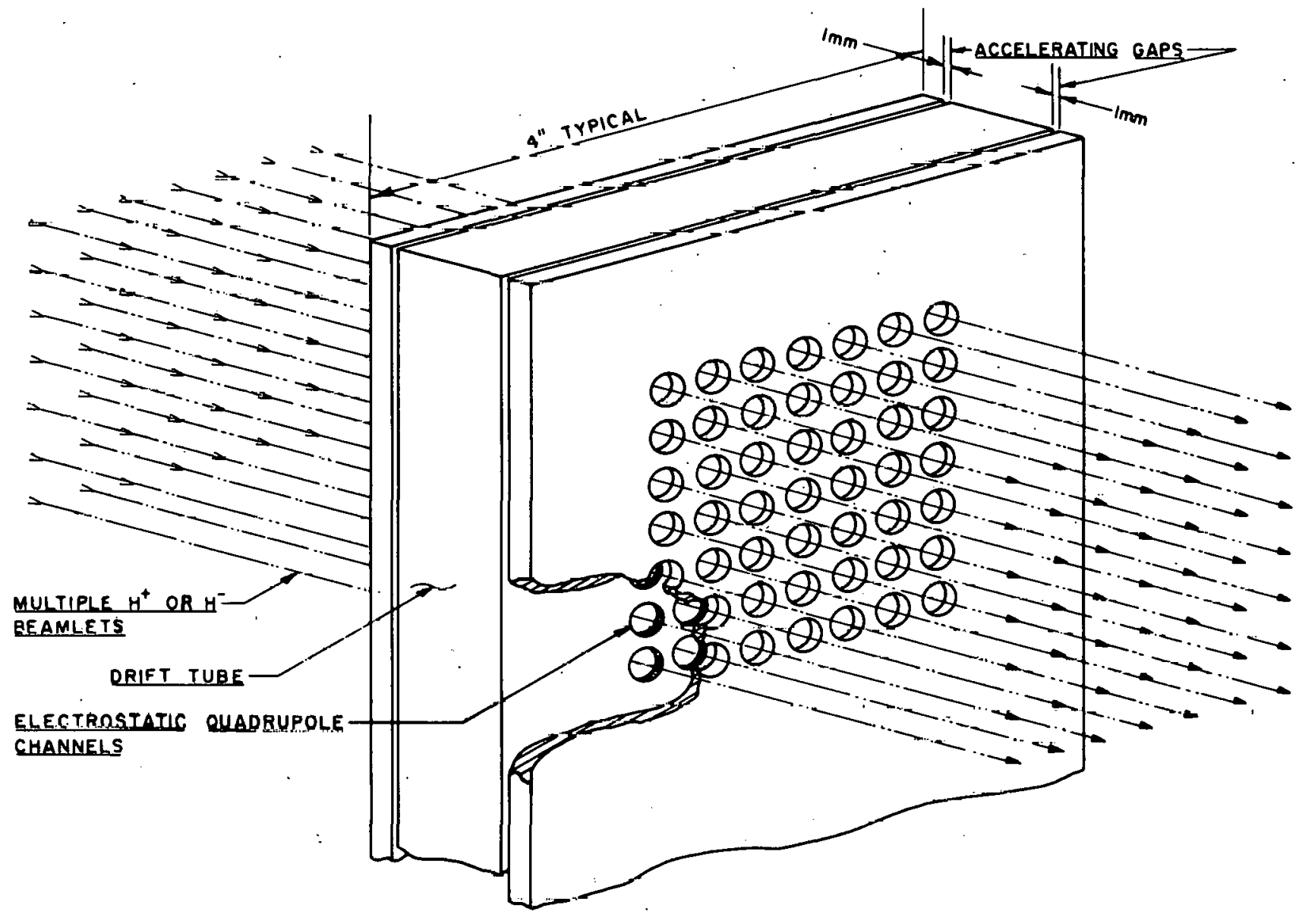

Figure 3, Multiple Beam Drift Tube and Accelerating Gaps 

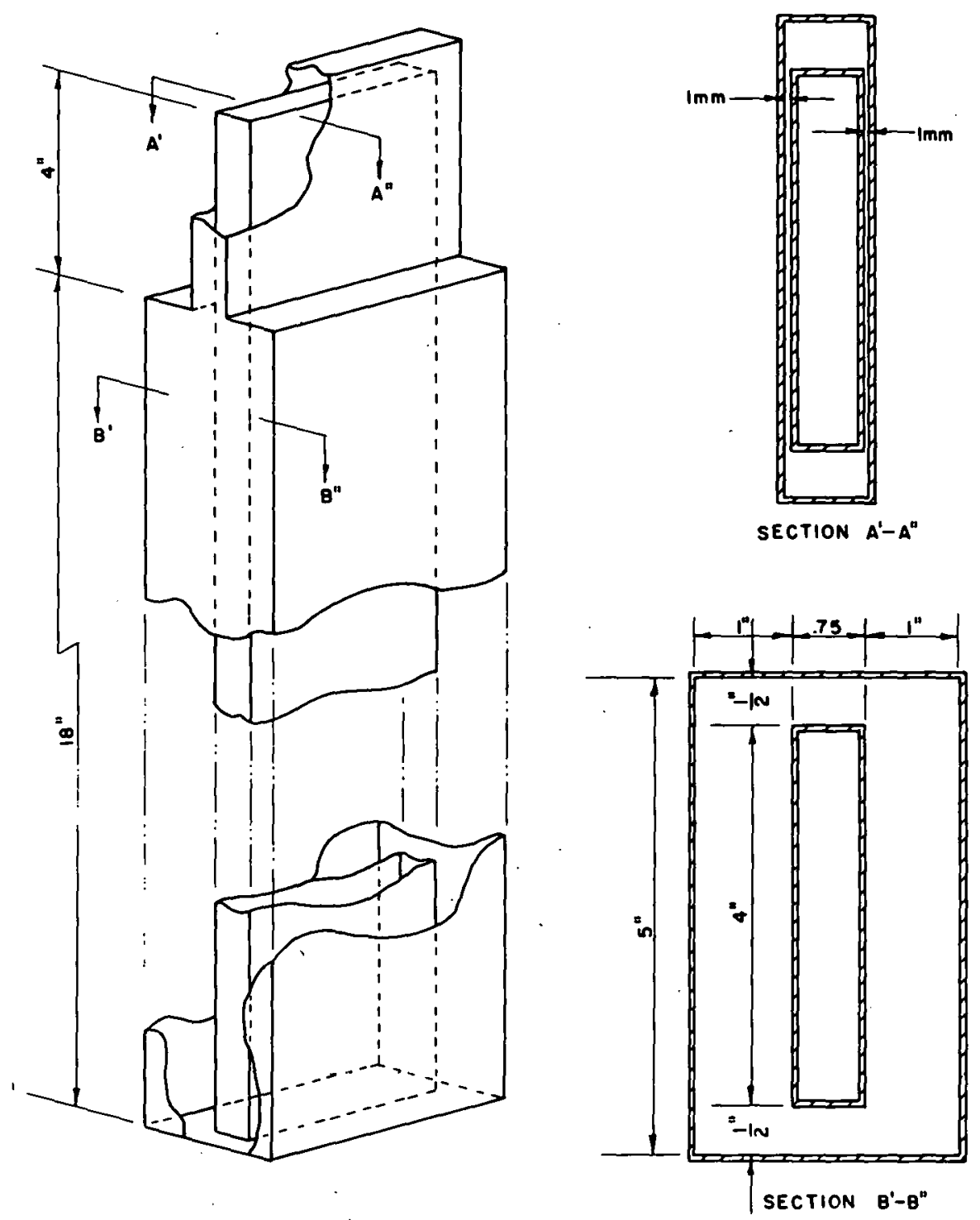

Figure 4. Rectangular Resonator for Low Level Measurements 


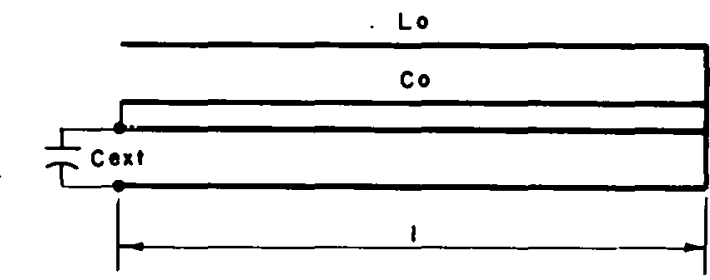

$C^{\prime}=\frac{1}{2}\left(\operatorname{cost}+\frac{\cos _{0} 1}{\sin ^{2} \theta}\right)$

$L^{\prime}=L_{0.1}$

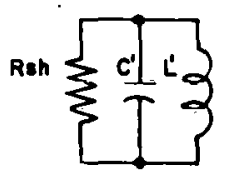

Figure 5. Lumped Circuit Equivalent of Distributed Resonator

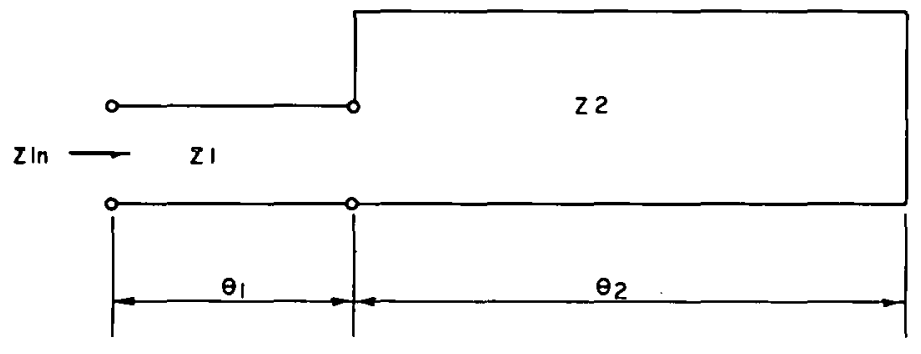

Figure 6. Compound Line

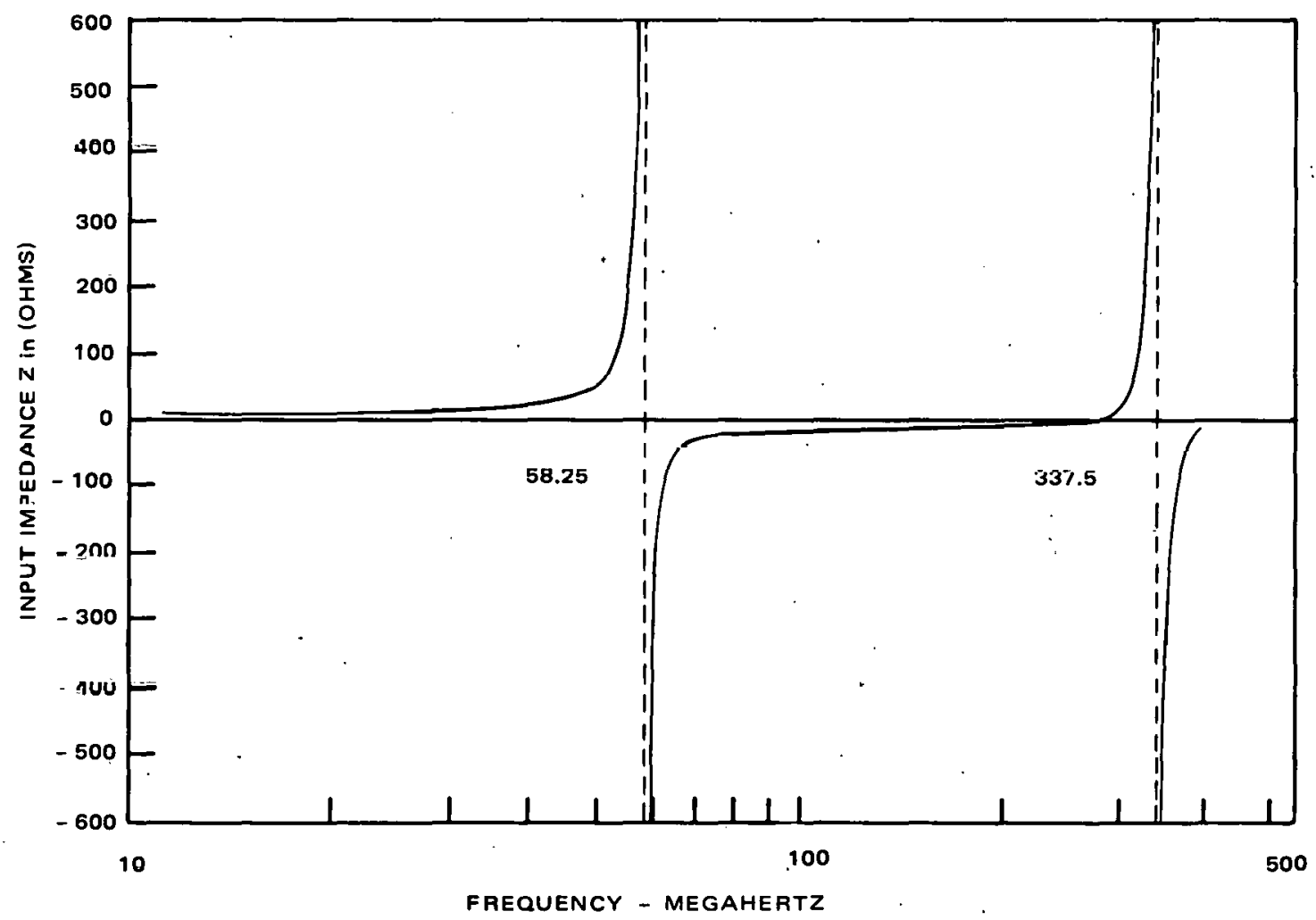

Figure 7. Input Impedance for a Compound Line 


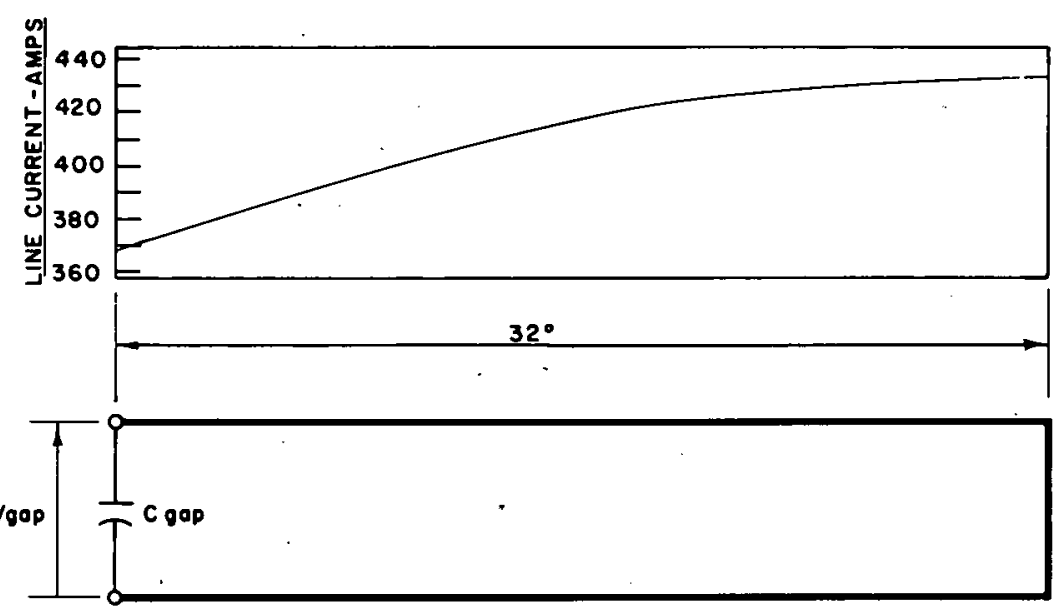

Figure 8. Rf Current Distribution in Capacitively Loaded Line
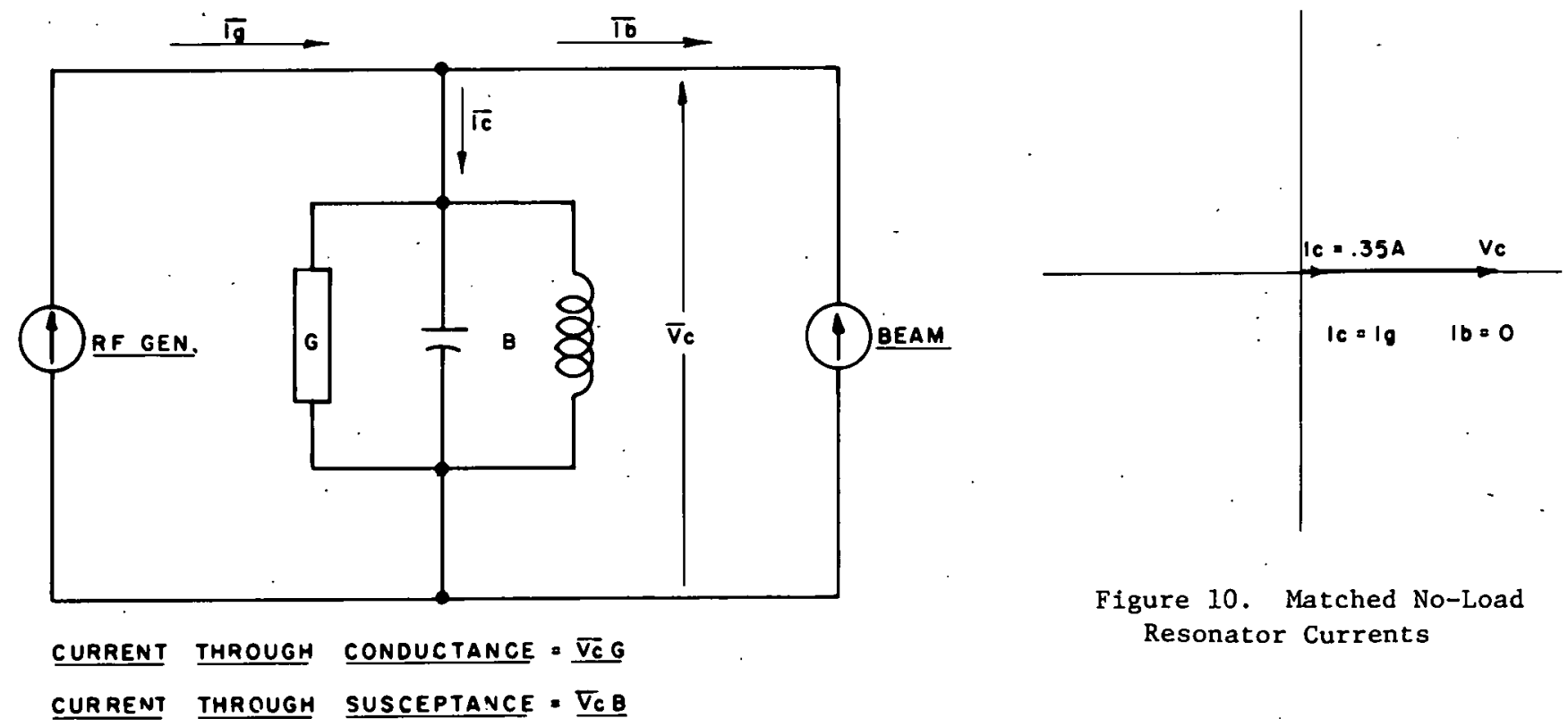

Figure 10. Matched No-Load Resonator Currents

Figure 9. Rf Generator, Resonator and Beam Circuit Mode1 

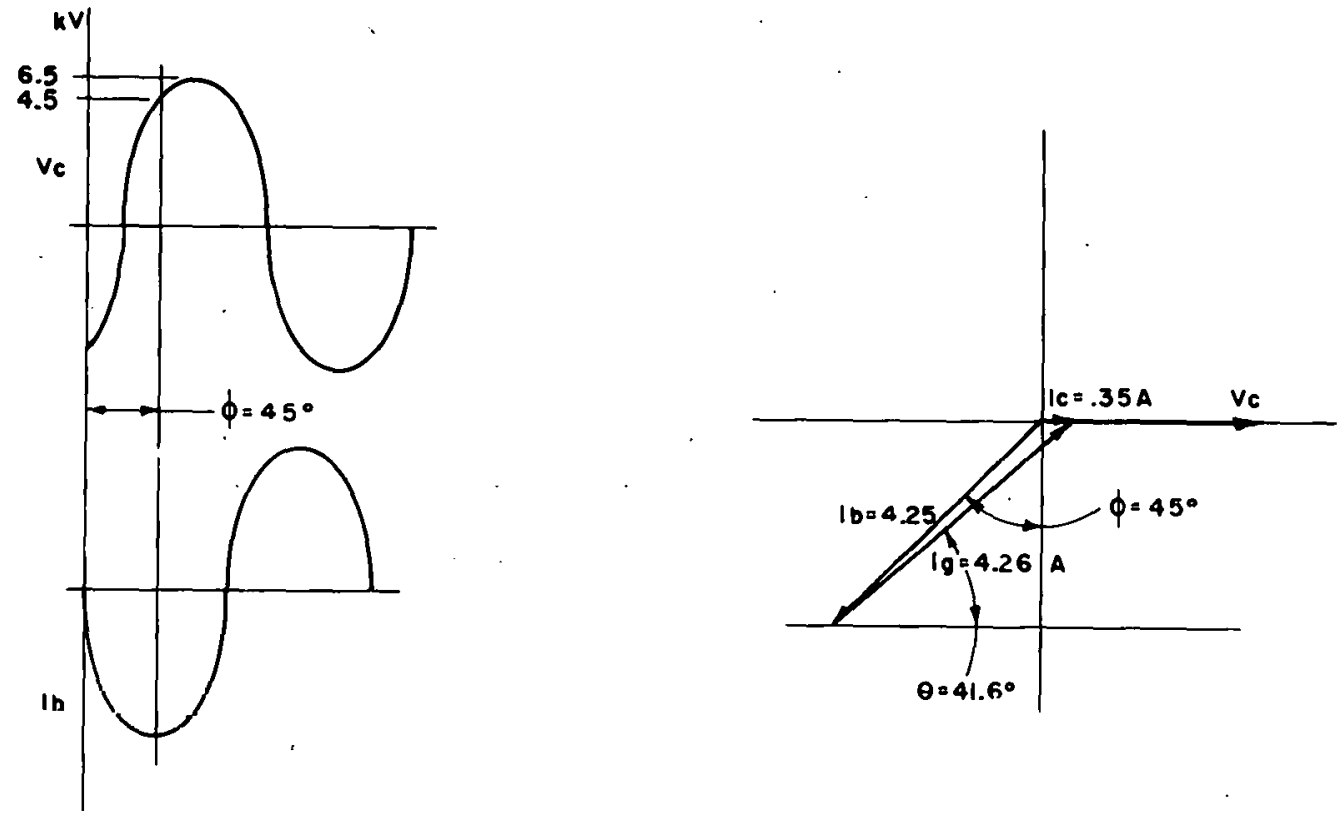

Figure 11. Tuned Resonator Currents with Beam

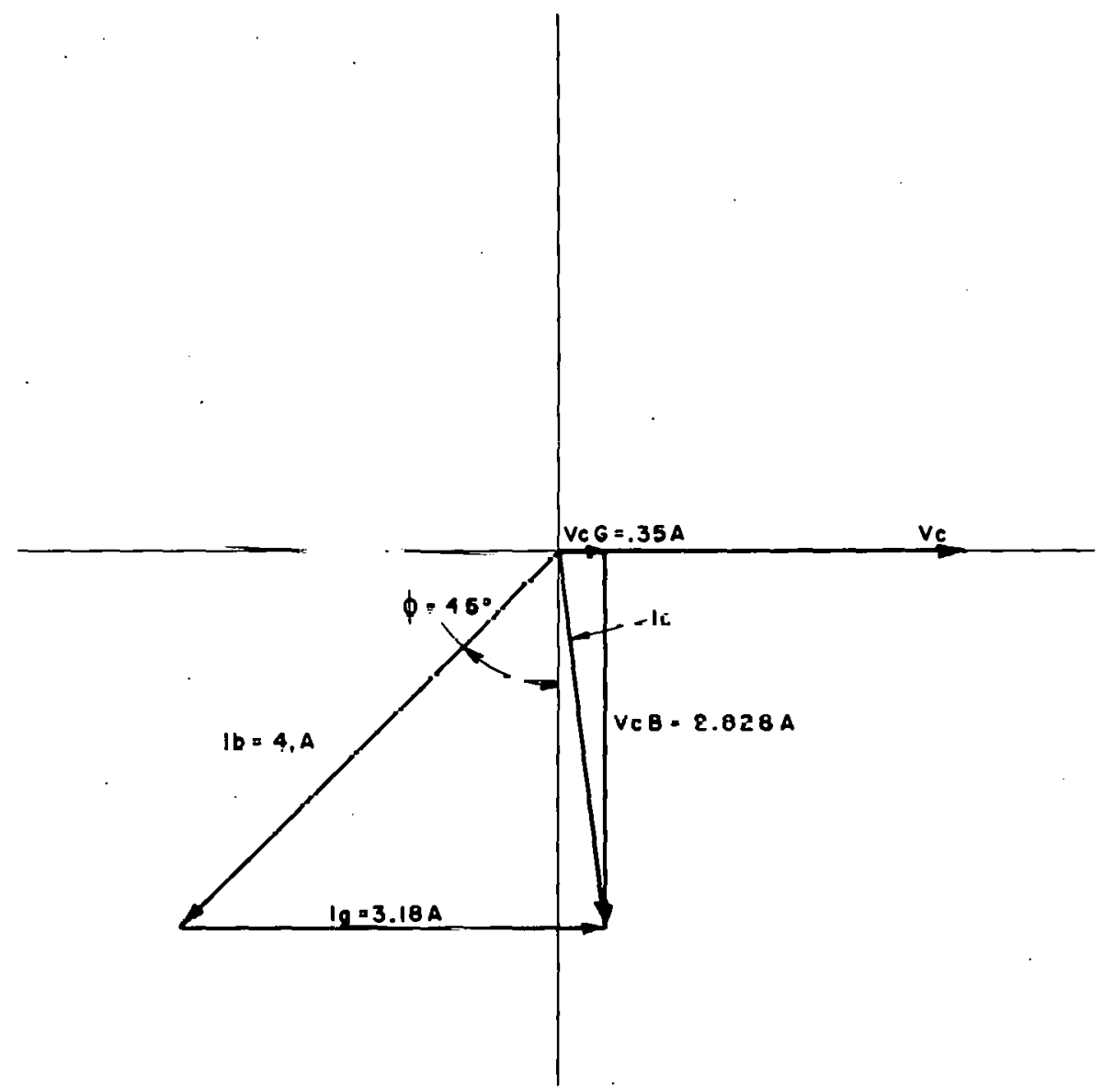

Figure 12. Detuned Resonator with Beam Loading 


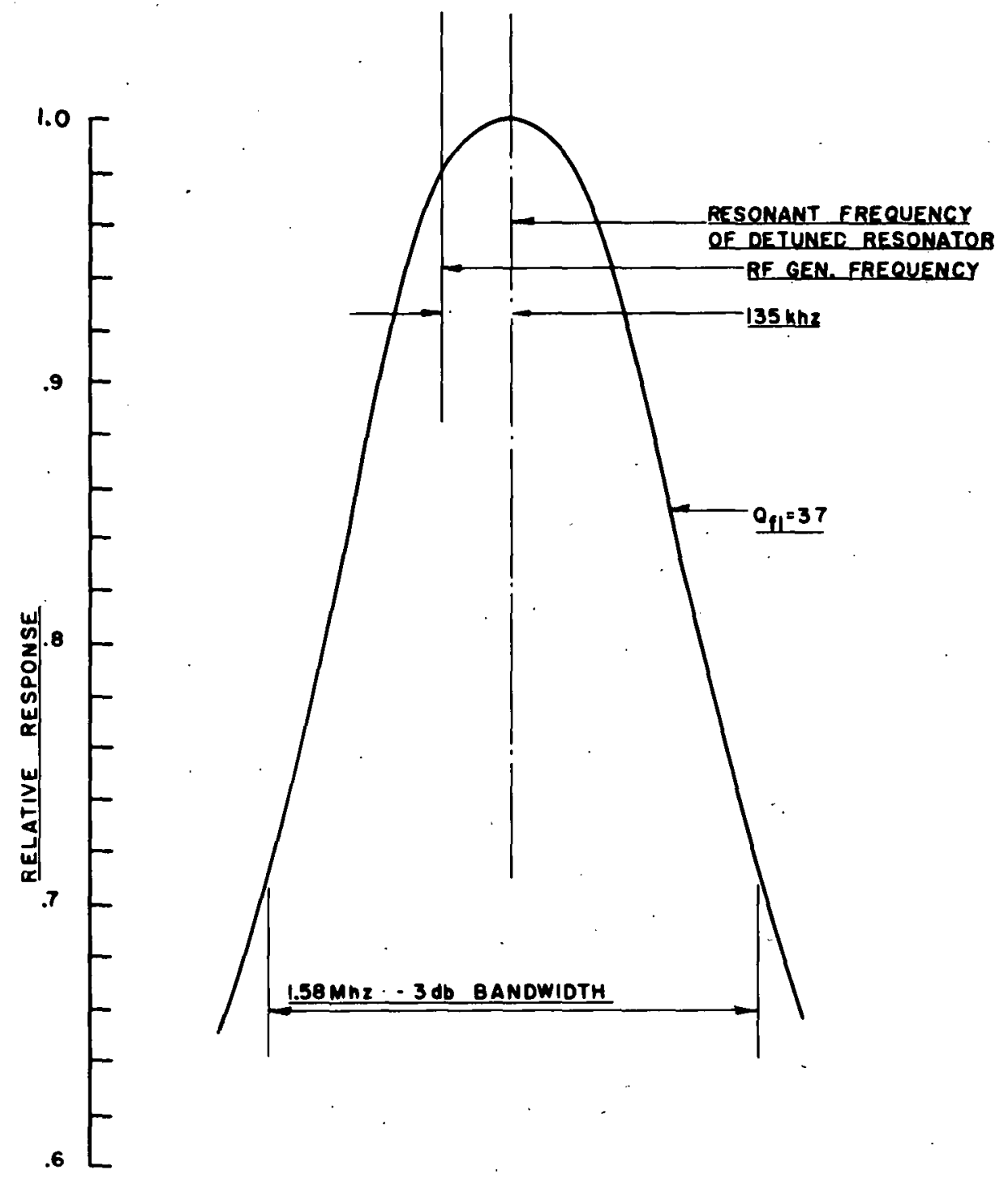

Figure 13. Relative Response of Detuned Resonator with Beam Loading 


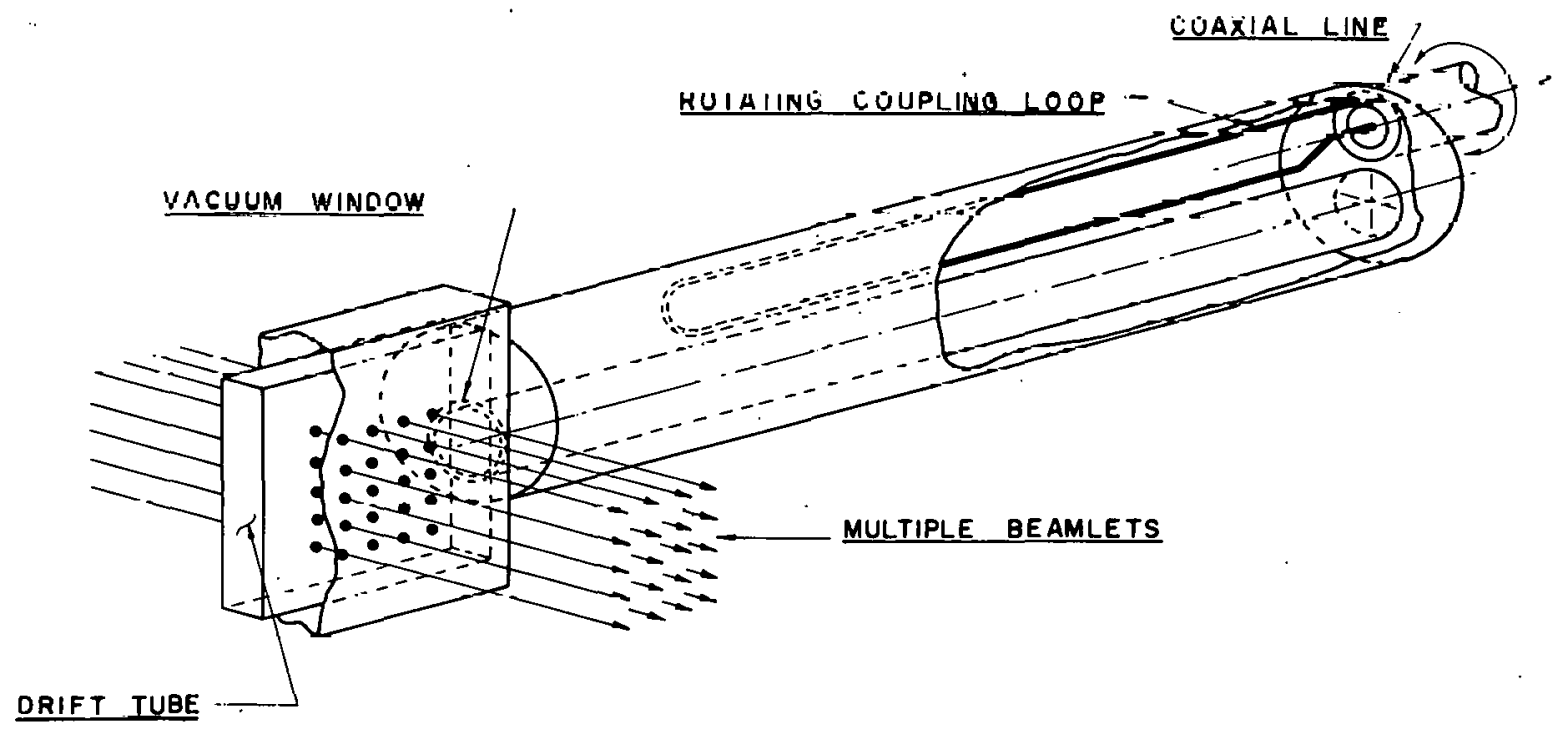

Figure 14. Accelerating Structure with Eccentric Line Resonator 


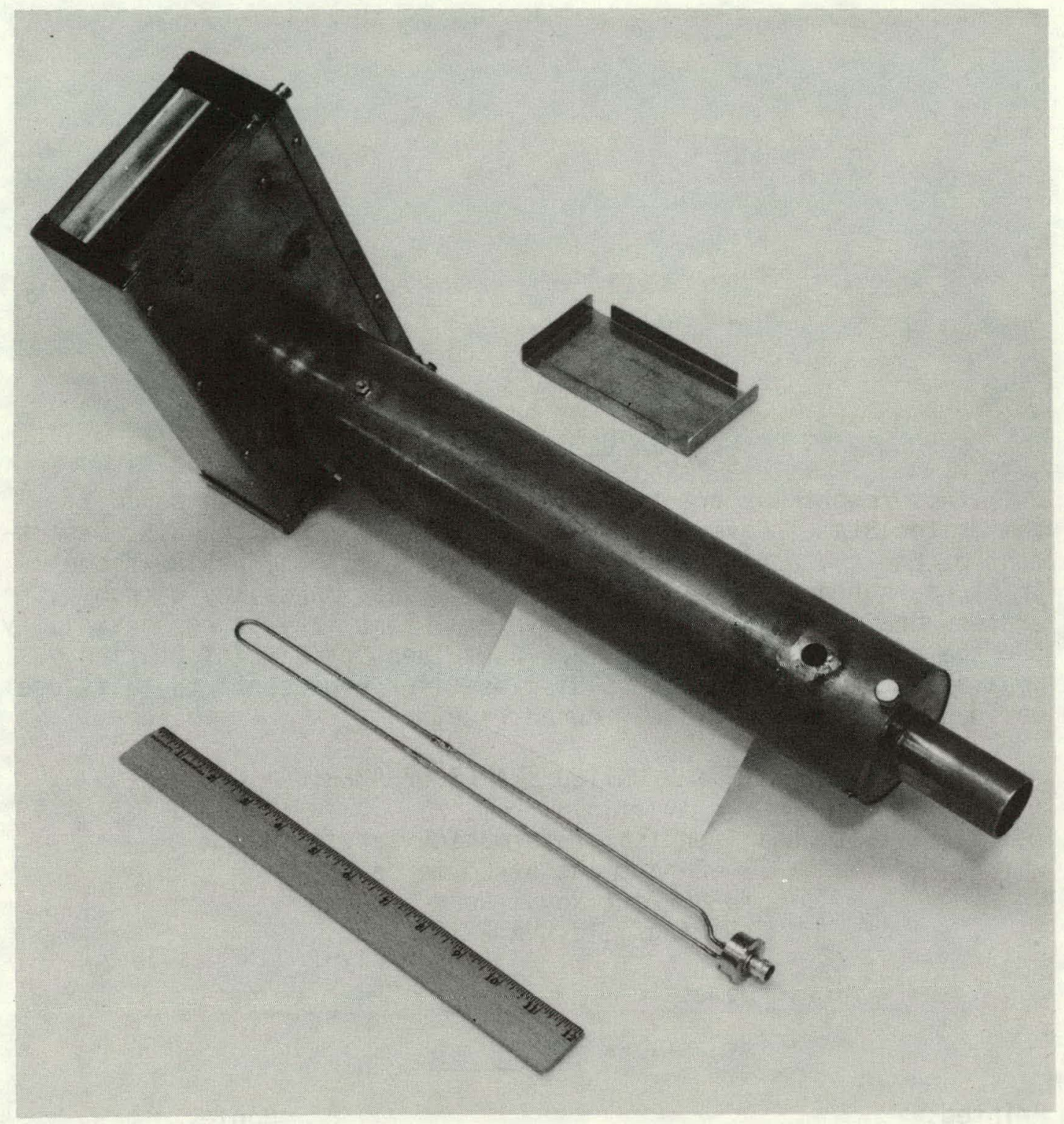

Figure 15. Eccentric Line Resonator 


\section{NOT I C E}

This report was prepared as an account of work sponsored by the United States Government. Neither the U.S. nor the U.S. Department of Energy, nor any of their employees, nor any of their contractors, subcontractors, or their employees, makes any warranty, express or implied, or assumes any legal liability or responsibility for the accuracy, completeness or usefulness of any information, apparatus, product or process disclosed, or represents that its use would not infringe privately owned rights.

$$
\begin{gathered}
\text { PRINTED IN THE UNITED STATES OF AMERICA } \\
\text { Available from } \\
\text { National Technical Intormation Service } \\
\text { U.S. Department of Commerce } \\
5285 \text { Port Royal Road } \\
\text { Springfield, VA } 22161
\end{gathered}
$$

Price: Domestic \$

Microfiche \$

Printed: 


\section{DISCLAIMER}

This book was prepared as an account of work sponsored by an agency of the United States Government. Neither the United States Government nor any agency thereof, nor any of their employees, makes any warranty, express or implied, or assumes any legal liability or responsibility for the accuracy, completeness, or usefulness of any information, apparatus, product, or process disclosed, or represents that its use would not infringe privately owned rights. Reference herein to any specific commercial product, process, or service by trade name, trademark, manufacturer, or otherwise, does not necessarily constitute or imply its endorsement, recommendation, or favoring by the United States Government or any agency thereof. The views and opinions of authors expressed herein do not necessarily state or reflect those of the United States Government or any agency thereof.

Printed in the United States of America Available from

National Technical Information Servire

U.S. Department of Commerce

5285 Port Royal Road

Springfield, VA 22161

Price: Printed Copy $\$ 4.50$; Microfiche $\$ 3.00$ 